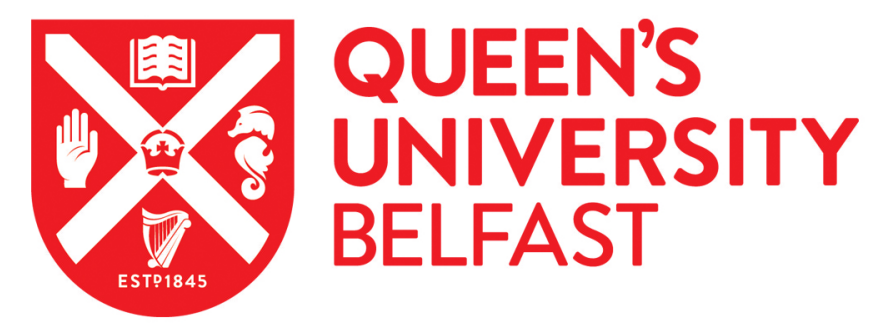

\title{
Effects of Gadolinium MRI Contrast Agents on DNA Damage and Cell Survival when Used in Combination with Radiation
}

Russell, E., McMahon, S. J., Russell, B., Mohamud, H., McGarry, C. K., Schettino, G., \& Prise, K. M. (2020). Effects of Gadolinium MRI Contrast Agents on DNA Damage and Cell Survival when Used in Combination with Radiation. Radiation Research, 194(3), 298-309. https://doi.org/10.1667/RADE-20-00008.1

Published in:

Radiation Research

Document Version:

Peer reviewed version

Queen's University Belfast - Research Portal:

Link to publication record in Queen's University Belfast Research Portal

Publisher rights

Copyright 2020 BioOne. This work is made available online in accordance with the publisher's policies. Please refer to any applicable terms of use of the publisher.

\section{General rights}

Copyright for the publications made accessible via the Queen's University Belfast Research Portal is retained by the author(s) and / or other copyright owners and it is a condition of accessing these publications that users recognise and abide by the legal requirements associated with these rights.

Take down policy

The Research Portal is Queen's institutional repository that provides access to Queen's research output. Every effort has been made to ensure that content in the Research Portal does not infringe any person's rights, or applicable UK laws. If you discover content in the Research Portal that you believe breaches copyright or violates any law, please contact openaccess@qub.ac.uk. 
Effects of Gadolinium MRI Contrast Agents on DNA Damage and Cell Survival when used in Combination with Radiation

${ }^{*}$ Emily Russell ${ }^{[1,2]}$, Stephen J. McMahon ${ }^{[1]}$, Ben Russell ${ }^{[2]}$, Hibaaq Mohamud ${ }^{[2]}$, Conor K. McGarry $^{[1,3]}$, Giuseppe Schettino ${ }^{[2,4]}$, Kevin M. Prise ${ }^{[1]}$; $^{*}$ Scholar In Training.

1. Patrick G Johnson Centre for Cancer Research, Queen's University Belfast, 97 Lisburn Road, Belfast, BT9 7AE, United Kingdom.

2. National Physical Laboratory, Teddington, TW11 OLW, United Kingdom.

3. Radiotherapy Physics, Northern Ireland Cancer Centre, Belfast Health and Social Care Trust, Belfast, United Kingdom.

4. University of Surrey, Department of Physics, Guilford, GU2 7XH, United Kingdom.

Running Title: Gadolinium MRI Contrast Agents on DNA Damage 
Russell, E. McMahon, S.J. Russell, B. Mohamud, H. McGarry, C.K. Schettino, G. H. Prise, K.M. Effects of Gadolinium MRI Contrast Agents on DNA Damage and Cell Survival when used in Combination with Radiation. Radiat. Res.

\section{Abstract}

Purpose

Gadolinium is a commonly used contrast agent for Magnetic Resonance Imaging (MRI). The aim of this work is to determine how MRI contrast agents affect radiosensitivity for tumour cells.

\section{Methods}

Using a $225 \mathrm{kVp}$ x-ray cabinet source, immunofluorescence and clonogenic assays were performed on 6 cancer cell lines: Lung (H460), Pancreas (MiaPaCa2), Prostate (DU145), Breast (MCF7), Brain (U87), and liver (HEPG2). Dotarem ${ }^{\circledR}$ contrast agent concentrations of $0.2 \mathrm{mM}$, $2 \mathrm{mM}$ and $20 \mathrm{mM}$ was used to determine its effect on DNA damage and cell survival. Measurements were performed using Inductively Coupled Plasma Mass Spectrometry (ICPMS) to determine the amount of gadolinium taken up by each cell line for each concentration.

\section{$\underline{\text { Results }}$}

A statistically significant increase in DNA damage was seen for all cell lines at a dose of 1Gy for concentrations of $2 \mathrm{mM}$ and $20 \mathrm{mM}, 1$ hour post-irradiation. 24 hours post-irradiation, most of the DNA damage had been repaired with the percentage repair around $90 \%$ for almost all doses of radiation and concentrations of Dotarem ${ }^{\circledR}$. Clonogenic results showed no statistically significant decrease in cell survival for any cell line or concentration. Uptake measurements showed cell line specific variations in uptake, with MCF7 and HEPG2 cells 
having a high percentage uptake compared to other cell lines, with $151.4 \pm 0.3 \times 10^{\wedge}-15 \mathrm{~g}$ and $194.8 \pm 0.4 \times 10^{\wedge}-15 \mathrm{~g}$ per cell respectively at $2 \mathrm{mM}$ Dotarem ${ }^{\circledR}$ concentration.

\section{$\underline{\text { Conclusion }}$}

This investigation found a variability in gadolinium uptake between cell lines. A significant increase was seen in initial levels of DNA damage at $1 \mathrm{~Gy}$ for all 6 cancer cell lines, however no significant decrease in cell survival was seen with the clonogenic assay. The observation of high levels of repair suggest that whilst initial levels of DNA damage are increased, this damage is almost entirely repaired within 24 hours, and does not affect the cells' ability to survive and produce colonies. 


\section{Introduction}

Magnetic Resonance Imaging (MRI) images are frequently obtained with the use of contrast agents, the most extensively used being gadolinium-based contrast agents (1). Alongside the development of MR-Linacs (a radiotherapy linear accelerator combined with an MRI scanner), gadolinium contrast agents are being investigated for their radiosensitising properties (2-4). Radiotherapy is used in the treatment of many cancers, yet it is often limited by the radiosensitivity of surrounding healthy tissue that may be damaged and lead to potential side effects. It is thought that gadolinium contrast agents may aid this process by radiosensitising the tumour (5), allowing a greater amount of DNA damage to occur within the tumour without increasing damage to the healthy tissue when the radiation is targeted towards the tumour. The ability of gadolinium to improve image contrast when used for MRLinacs allows the possibility for gadolinium contrast agents to be used both diagnostically and therapeutically, so-called a theranostic agent.

Gadolinium is utilised as an MRI contrast agent due to its strongly paramagnetic properties, with its 7 unpaired electrons (6). The paramagnetic properties reduce MRI relaxation times, even at low concentrations, and is very stable when chelated as well as being well tolerated by humans (7). However, recent studies have reported toxicity and DNA damage caused by commonly used gadolinium contrast agents used for contrast-enhanced MRI scans $(8,9)$. This toxicity was found to be dependent on the chemical structure of the contrast agent, with linear structures showing more toxicity compared to macrocyclic (8). In the case of Dotarem ${ }^{\circledR}$, the gadolinium is chelated into a macrocyclic ionic complex using an organic acid named DOTA, but other gadolinium contrast agents have differing structures, and this reported toxicity has mostly been attributed to gadolinium becoming disassociated from the complex, and not being removed from the body by the kidneys as efficiently Corresponding Author: Emily Russell. Contact Information; erussell11@qub.ac.uk, PGJCCR 97 Lisburn Road Belfast BT9 7AE. 
previously predicted $(8,10,19,11-18)$. Gadolinium toxicity may become of even greater importance with MR-Linacs, when MRI is combined with radiotherapy. The toxicity cause by contrast agents commonly used for MRI, in particular gadolinium, may add to the damaging effects of radiotherapy on the tumour, making the treatment more efficacious. Little is reported on the potential radiosensitising effects of commonly used conventional MRI contrast agents when combined with clinical levels of radiation and magnetic fields. It has led to research investigating how gadolinium effects treatment plans, both physically and biologically, and how treatment planning parameters must be altered accordingly $(20,21)$.

High Z number elements, including gadolinium, are potential radiosensitisers, as they strongly absorb radiation (22), producing many more secondary electrons, allowing for many more collisions and ionisations with cancer cells, leading to increased levels of DNA damage. This is of greater significance at lower kV energies, where the photon interactions are predominantly due to the photoelectric effects, with an absorption coefficient that is proportional to $Z^{3}$. This has the potential to increase tumour control, and therefore, for accurate treatment planning, it is essential to know the extent of radiosensitisation caused by commonly used gadolinium-based contrast agents.

Research within the literature regarding gadolinium as a radiosensitiser appears to be developing around nanoparticle contrast agents, particularly for their preferential uptake in tumours $(2,3,23-26)$. This is caused by the Enhanced Permeability and Retention (EPR) effect in which the leaky tumour vasculature allows uptake of the nanoparticles into the tumour that would not be able to permeate other tissues (27), by their 'vascular permeability to macromolecules' (28). Also, they are not removed from the body as would be expected, as their size is too large for renal clearance (29). Nanoparticles cause toxicity to tumour cells by causing free radical damage by reactive oxygen species (ROS), leading to DNA damage and Corresponding Author: Emily Russell. Contact Information; erussell11@qub.ac.uk, PGJCCR 97 Lisburn Road Belfast BT9 7AE. 
apoptosis, among many other mechanisms (30). The hope is that this will increase radiosensitivity, increase cell kill and tumour control, leading to overall increased levels of survival amongst patients.

There is currently a paucity of data investigating radiosensitivity caused by conventional gadolinium-based contrast agents, although one in vitro study from Taupin et al. indicated that radiosensitising effects by both conventional and nanoparticle contrast agents are dependent on the radiation energy, and that different mechanisms may be responsible for the variations in radiosensitivity between different contrast agents (4). One limitation of this investigation is that rat F98 glioma cells were used, as opposed to human cells, which may be affected differently in response to the gadolinium. It was found that the nanoparticles caused more radiosensitisation than the conventional contrast agents when the same concentration was used and that, at $1.25 \mathrm{MeV}$, only the nanoparticles showed a significant radiosensitisation. The maximum sensitisation-enhancement ratio at $4 \mathrm{~Gy}$ was found to be at $65 \mathrm{keV}$, suggesting perhaps that conventional gadolinium radiosensitisers are only efficacious at lower energies. This may be due to the Gadolinium K-edge being at $50.2 \mathrm{keV}$ (31). This may become of greater importance when deciding whether to use conventional or nanoparticle contrast agents to be used in combination with an MR-Linac. MR-Linacs would typically use $6 \mathrm{MV}$ energy, and therefore, according to the study by Taupin et al., it may be that only gadolinium nanoparticles are a viable option for therapy, even at an energy much higher than the K-edge of Gadolinium, as they showed radiosensitisation at both the low and high energies (4).

Due to this gap in the literature of radiosensitising effects with conventional gadolinium contrast agents, investigations across multiple tumour types are essential to improve radiotherapy. Therefore, this study utilises a commonly used gadolinium-based contrast Corresponding Author: Emily Russell. Contact Information; erussell11@qub.ac.uk, PGJCCR 97 Lisburn Road Belfast BT9 7AE. 
agent, Dotarem ${ }^{\circledR}$ (Guerbet, US). It investigates clonogenic cell survival and DNA damage caused by the combination of $\mathrm{kV}$ radiation with varying concentrations of Dotarem ${ }^{\circledR}$. Dotarem ${ }^{\circledR}$ is a compound of Gadoterate Meglumine. It has the molecular formula $\mathrm{C}_{23} \mathrm{H}_{42} \mathrm{GdN}_{5} \mathrm{O}_{13}$, and as Gadolinium is toxic, it must be chelated, in this case, to DOTA (32). Gadolinium contrast agents come in 2 main structures, linear and macrocyclic, of which Dotarem $^{\circledast}$ is the latter, meaning that the ligand forms a cage around the ion (33). The ionic nature of Dotarem ${ }^{\circledR}$ makes it more stable as it has an overall charge so bind more strongly (33). 6 cancer cell lines were selected for 6 different potential treatment sites, and the uptake of Dotarem ${ }^{\circledR}$ for each cell line was investigated using ICP-MS.

\section{Materials and Methods}

\subsection{Cell Line Selection and Tissue Culture}

For clinical relevance, 5 cell lines were selected to represent 5 treatment sites outlined by the MRI-Linac Accelerator Consortium (34). The cell lines selected were; H460 large cell lung cancer, MiaPaCa2 pancreatic carcinoma, DU145 prostate carcinoma, MCF7 breast adenocarcinoma, U87 brain glioblastoma. However, there have recently been a number of papers within the literature in regards to the liver being a potential treatment site for MRLinacs (35-40), and so a $6^{\text {th }}$ cell line, HEPG2 liver carcinoma, was used.

All cell lines were acquired from the American Type Culture Collection (ATCC) and incubated at $37.5^{\circ} \mathrm{C}$ at $5 \% \mathrm{CO}_{2}$. The cells were incubated in $\mathrm{T} 75$ vented flasks (Nunc EasYFlask $^{T M}$, ThermoFisher) in $12 \mathrm{ml}$ media, and sub-cultured every 3-4 days. Cell lines $\mathrm{H} 460$, MCF7, U87 and HEPG2 were cultured in Dulbecco's Modified Eagle Media (DMEM) Corresponding Author: Emily Russell. Contact Information; erussell11@qub.ac.uk, PGJCCR 97 Lisburn Road Belfast BT9 7AE. 
(ThermoFisher). MiaPaCa2 cells were cultured in a High Glucose DMEM media that, and DU145 cells were cultured in Roswell Park Memorial Institute (RPMI) media (ThermoFisher), All media was supplemented with 10\% Fetal Bovine Serum (FBS) (ThermoFisher) and 1\% Penicillin Streptomycin (Pen-Strep) (ThermoFisher).

\subsection{Quantification of uptake}

The effectiveness by which Dotarem ${ }^{\circledR}$ is actively taken up by cells was assessed by inductively coupled plasma mass spectrometry (ICP-MS) (Aligent 8800, Aligent Technologies, UK). 1 million cells were seeded in $30 \mathrm{~mm}$ petri dishes, in $2 \mathrm{ml}$ media. After 24 hours, media was removed and a solution of media and Dotarem ${ }^{\circledR}$ was added at the desired concentrations $(0.2 \mathrm{mM}, 2 \mathrm{mM}$ and $20 \mathrm{mM})$, with $2 \mathrm{ml}$ per dish. After a further 24 hours of incubation, the media/Dotarem ${ }^{\circledR}$ solution was removed, cells were washed with PBS, trypsinised and counted using a Z1 Coulter Particle Counter (Beckman Coulter) to determine cell density. Cells were placed in a centrifuge (Centrifuge 5702, Eppendorf) for 8 minutes at $1500 \mathrm{rpm}$ and the pellet resuspended in $500 \mu$ l of deionised water, before being left to evaporate overnight.

$500 \mu$ of Aqua Regia solution ( $3: 1$ hydrochloric acid : nitric acid) was added to the evaporated solution, and left in a fume hood overnight, so that the cell residue was fully solubilised, and only the gadolinium was left behind. This was finally resuspended in $30 \mathrm{ml}$ of deionised water in order for the measurement to take place.

The ICP-MS instrument was fitted with a quartz double-pass spray chamber and a MicroMist nebuliser (Glass Expansion, Melbourne, Australia) and nickel sample and skimmer cones (Crawford Scientific, South Lanarkshire, UK). Samples were prepared in deionised water and ran in single quad mode (Q1) without the reaction cell on. This was in accordance with Corresponding Author: Emily Russell. Contact Information; erussell11@qub.ac.uk, PGJCCR 97 Lisburn Road Belfast BT9 7AE. 
the setup described in Russell et al. (41). The ICP-MS is equipped with an autosampler where samples can be positioned in the desired order, allowing processing of all samples in a single run. A blank sample containing deionised water was the first sample run to determine the instrument background, and the sample was run after 3 consecutive samples, in order to monitor any gadolinium contamination. Between every sample, the autosampler probe was automatically rinsed in $0.3 \mathrm{M} \mathrm{HNO}_{3}$ and then deionised water to minimise the risk of crosscontamination. One gadolinium standard sample was retested after every 5 samples to monitor instrument drift and to ensure gadolinium was not dropping out of solution during the run. If any dropout was detected, this could be calculated for.

The counts per second (CPS) found by ICP-MS were compared to a calibration curve determined using samples containing known concentrations of Dotarem ${ }^{\circledR}$, ranging from $5 \times 10^{-}$ ${ }^{8} \mathrm{mM}$ to $5 \times 10^{-3} \mathrm{mM}$, in order to determine the concentration of Dotarem ${ }^{\circledR}$ contained in each sample. Analysis was performed to determine the mass of gadolinium detected within each cell.

\subsection{Immunofluorescence Assay}

For quantification of DNA damage, 53BP1 was quantified using an immunofluorescence assay in all 6 cell lines. Cells were seeded into 6 -well plates, at $1.5 \times 10^{5}$ cells per well and with $2 \mathrm{ml}$ of the appropriate media. Before seeding, each well had a sterilised glass cover slip (VWR, UK) placed at the bottom for the cells to adhere to. Cells were washed in Phosphate Buffered Solution (PBS) and detached from the flask using trypsin.

The cells were seeded 24 hours prior to the Dotarem ${ }^{\circledR}$ being added to the cells, and incubated for a further 24 hours before irradiating. This ensures that the cells had time to Corresponding Author: Emily Russell. Contact Information; erussell11@qub.ac.uk, PGJCCR 97 Lisburn Road Belfast BT9 7AE. 
adhere to the surface of the cover slip and also that gadolinium uptake would have occurred. Cells were exposed to doses of 0, 1 and $2 \mathrm{~Gy}$ of $225 \mathrm{kVp}$ X-rays provided by an XRAD cabinet source, with an SSD of $50 \mathrm{~cm}$ and a dose rate of $0.589 \mathrm{~Gy} / \mathrm{min}$. A $2 \mathrm{~mm} \mathrm{Cu}$ copper filter was used for filtration of the beam, giving a final half value layer (HVL) of 2.3 $\mathrm{mm} \mathrm{Cu}$. For each dose, cells were exposed to 3 concentrations of Dotarem ${ }^{\circledR}: 0.2 \mathrm{mM}, 2 \mathrm{mM}$, $20 \mathrm{mM}$. Cells with no added contrast medium were used as controls. After irradiation, Dotarem ${ }^{\circledR}$ was washed off and fresh media was added before being incubated until the fixation time points of 1 hour and 24 hours post-irradiation, in order to investigate both the immediate DNA damage caused by the exposures, and also the repair that had occurred over a 24 hour period. Cells were fixed with $2 \mathrm{~mL}$ of ice-cold fixative with a 50:50 ratio of methanol to acetone, and incubated at $4^{\circ} \mathrm{C}$ for 10 minutes before washing with PBS. Cells were blocked using a solution of 5\% FBS and $0.5 \%$ Triton X-100 in PBS, and a primary anti53BP1 antibody derived from rabbits (Novus, UK) was used at a concentration of 1:3000 in solution with blocking buffer. The DNA double strand breaks were labelled using a 53BP1 antibody. 53BP1 is a protein that binds to P53 (42) and promotes end-joining of DNA (43), so its presence indicates the site of a double strand break.

A goat-anti-rabbit (GAR 488) secondary antibody was used to fluorescently label the primary antibody at a ratio of 1:2000 in blocking buffer. Cover slips were mounted onto slides using mounting media (Prolong Gold with DAPI), and stored at $-20^{\circ} \mathrm{C}$. This assay was carried out for 3 repeats.

\subsection{DNA Damage Quantification}


The stained slides were investigated using a Zeiss Axiovert 200M confocal microscope, at a magnification of $x 63$, and imaged using AutoVision software to identify the presence of 53BP1 foci within the cells. The number of foci was counted within a sample of 50 cells, for 3 repeats. Cells were rejected from counting if they were enlarged, contained large numbers of foci, fragmented chromosomes, or undergoing apoptosis. This equated to an average of $8 \%$ of the nuclei across all slides. Each foci counted represented a DNA DSB.

\subsection{Analysis of DNA Damage}

A two-tailed T test was carried out to determine significance between samples with no added Dotarem ${ }^{\circledR}$ compared to each off the concentrations used. The mean number of foci and standard error were calculated for both 1 hour and 24 hours post-irradiation, to determine initial levels of DNA damage, as well as longer term effects.

\subsection{Clonogenic Assay}

The clonogenic assay was used to assess the ability of the cells to repair radiation damage and produce colonies, with the number of colonies used as a measure of the cell survival. The experiment was carried out for all 6 cell lines, at 4 different dose points: 0 Gy, $2 \mathrm{~Gy}, 4 \mathrm{~Gy}$ and $8 \mathrm{~Gy}$, and at 4 different concentrations of Dotarem ${ }^{\circledR} ; 0 \mathrm{mM}, 0.2 \mathrm{mM}, 2 \mathrm{mM}$ and $20 \mathrm{mM}$. Cells were plated into 6-well plates, with cell numbers 500 for 0 and 2 Gy, 1000 for 4 Gy and 2000 for $8 \mathrm{~Gy}$, with $2 \mathrm{ml}$ of media. 24 hours after seeding, the Dotarem ${ }^{\circledR}$ was added into the media, 24 hours prior to irradiating using $225 \mathrm{kVp} x$-rays. 
After irradiation, the media containing the Dotarem ${ }^{\circledR}$ was removed and replaced with fresh media. Colonies were stained using Crystal Violet (0.4\% in $95 \%$ Ethanol) after an incubation time that varied between cell line. The incubation times were: $\mathrm{H} 460-6$ days, MiaPaCa2 - 7 days, DU145 - 7 days, MCF7 - 8 days, U87 - 7 days, HEPG2 - 13 days. Incubation times we chosen based on the doubling times of each cell line, and how quickly colonies would be formed.

Following staining of the cells, the number of colonies were manually counted in each well. A colony was determined to be a group of $>50$ cells, and the average was taken over all 3 repeats. The plating efficiency was calculated as a percentage of the number of colonies counted relative to the original number of cells plated. This was then used to calculate the surviving fraction, a measure of the plating efficiency at a given dose relative to the plating efficiency of control cells.

The surviving fractions were then plotted as a Clonogenic Survival curve using GraphPad Prism, with a curve fitted used the Linear Quadratic Model. This gives a representation of how an increasing dose effects the surviving fraction for each cell line. The Linear Quadratic Model is fitted using Equation 1, where S is the surviving fraction, $D$ is the dose (Gy) and $\alpha$ and $\beta$ are the linear and quadratic coefficients of cell death (44).

$$
S=\exp \left(-\alpha D-\beta D^{2}\right)
$$

In order to determine whether there is any statistical difference in the cell survival curves, Extra-Sum-of-Squares F Testing was carried out. It tests whether any data set is different from all of the others by calculating whether the curve fit of one curve would accurately fit all of the other curves.

Corresponding Author: Emily Russell. Contact Information; erussell11@qub.ac.uk, PGJCCR 97 Lisburn Road Belfast BT9 7AE. 
The Dose Enhancement Factor (DEF) was then calculated as a ratio of the dose without radiation compared to the dose with Dotarem ${ }^{\circledR}$ required to create the same biological effect. The survival fraction at $8 \mathrm{~Gy}$ was used for the calculation. A DEF of 1 represents the same biological effect at equal doses.

\subsection{Predicted Dose Enhancement Factor}

The predicted DEF for a $225 \mathrm{kVp}$ spectrum was approximated based on the ratio of the energy absorbed in the medium plus gadolinium to that absorbed in the medium alone. To estimate this, the ratio between the mass energy absorption coefficient for gadolinium and water was calculated at a range of energies. This was then scaled by the fluence of the Xray spectrum at each energy to provide an absorption ratio for pure water and pure gadolinium. Finally, the DEF within each sample was calculated by taking into account the density of Dotarem to calculate the absorption in each same composition.

\section{Results}

\subsection{Quantification of Uptake}

All cell types tested showed uptake of gadolinium, reaching values ranging from 149 $\pm 40 \times 10^{-15} \mathrm{~g}$ for H460s to $1068 \pm 236 \times 10^{-15} \mathrm{~g}$ in DU145 cells for $20 \mathrm{mM}$ concentration. The average mass of gadolinium detected per cell for increasing concentrations of Dotarem ${ }^{\circledR}$ is presented in Figure 1. It shows that $\mathrm{H} 460$ and MiaPaCa2 cells consistently absorbed relatively low masses of gadolinium compared to other cell lines, for all concentrations. MCF7 and Corresponding Author: Emily Russell. Contact Information; erussell11@qub.ac.uk, PGJCCR 97 Lisburn Road Belfast BT9 7AE. 
HEPG2 cells took up high masses of gadolinium at all concentrations in comparison to the other cell lines, particularly at 2 mM. However, DU145 cells were the outliers in this scenario, taking up much more gadolinium at $20 \mathrm{mM}$ concentration, when compared directly to the other cell lines, than at lower concentrations. The overall trend, however, is of an increasing mass of gadolinium taken up into the cells with increasing concentrations of Dotarem ${ }^{\circledR}$.

\subsection{Immunofluorescence Assay}

\subsubsection{Inherent Effect of Dotarem ${ }^{\circledR}$ on DNA Damage}

Figure 2 shows the level of DNA damage in each cell line exposed to different concentrations of Dotarem ${ }^{\circledast}$, in the absence of radiation. The same trend for all cell lines, an increase in DNA damage for an increasing concentration of Dotarem ${ }^{\circledR}, 1 \mathrm{hr}$ post-irradiation. There is a small but statistically significant increase at $20 \mathrm{mM}$ for all cell lines, and at $2 \mathrm{mM}$ for 5 cell lines (MiaPaCa2, DU145, MCF7, U87 and HEPG2), with MCF7 cells having a significant increase at all concentrations of Dotarem ${ }^{\circledR}$.

\subsubsection{Combination of Dotarem ${ }^{\circledR}$ with $225 \mathrm{kVp}$ X-Rays on DNA Damage}

In order to determine if Dotarem ${ }^{\circledast}$ acts to sensitise the cells to radiation and increase DNA damage, foci counted at 1 hour after doses of $1 \mathrm{~Gy}$ and $2 \mathrm{~Gy}$ doses where determined for all different Dotarem ${ }^{\circledR}$ concentrations. These are presented in Figure 3.

The graphs show that for a dose of $1 \mathrm{~Gy}$, every cell line had a significant increase $(P<$ 0.0001 ) in the number of foci counted at the $20 \mathrm{mM}$ concentrations, when compared to the Corresponding Author: Emily Russell. Contact Information; erussell11@qub.ac.uk, PGJCCR 97 Lisburn Road Belfast BT9 7AE. 
same dose without Dotarem ${ }^{\circledR}$ present. The percentage increase in the number of foci at 20 $\mathrm{mM}$ compared to controls was consistent across all cell lines, with a range from $22.5-34.8 \%$. The same trend was seen for $2 \mathrm{~Gy}$ at 1 hour post radiation for every cell line except for U87 and HEPG2 cells which had a smaller, but still significant, increase in DNA damage.

\subsubsection{Effects on DSB Repair}

Figure 4 shows there are significant changes in DNA damage at 24 hours for all cell lines to a varying extent, with significant increases seen primarily with MiaPaCa2, DU145, MCF7, and HEPG2 cells. Compared to the number of foci counted for the 0Gy control values, there are obvious increases in DNA damage for all cell lines with radiation, however it is important to mention that the actual numbers of foci counted were small after the 24 hour repair period. For all cell lines, almost all of the DNA damage has been repaired, with repair percentages above $90 \%$ for the vast majority of concentrations and doses, with exceptions being MCF7 and HEPG2 cells. This suggests that, although Dotarem ${ }^{\circledR}$ increases initial DNA damage, this damage is repairable by all cell lines, with less than $20 \%$ of the damage still remaining after 24 hours for all cell lines.

\subsection{Uptake vs DNA damage}

Figure 5 shows the gadolinium mass taken up per cell against the number of DNA damage foci, for doses of 0,1 and $2 \mathrm{~Gy}$, in order to determine whether there is a correlation between the mass of gadolinium taken up, and the amount of DNA damage caused by the combination of Dotarem ${ }^{\circledR}$ and radiation. For all doses, the number of foci appears to Corresponding Author: Emily Russell. Contact Information; erussell11@qub.ac.uk, PGJCCR 97 Lisburn Road Belfast BT9 7AE. 
increase with increasing mass of gadolinium uptake. The Pearson correlation coefficients for each cell line ranged from $0.76-0.96$, indicating a strong correlation for all cell lines, with the highest being the H460s and MCF7 cells. However, with the small sample size of concentrations, no statistical analysis was able to performed to indicate the significance of this. The effect appears more pronounced for certain cell lines, particularly MCF7 cells, in which the number of foci counted is increasing quite substantially with increasing gadolinium mass, with an extra 10-20 foci for doses of 1 and $2 \mathrm{~Gy}$.

\subsection{Clonogenic Assay}

Clonogenic survival for each cell line is shown in Figure 6, and fitted using the Linear Quadratic Model. $\alpha / \beta$ ratios are shown in Table 1.

The Extra-sum-of-squares $\mathrm{F}$ test revealed no significant change in any of the curves from each other, $P>0.05$. Therefore, Dotarem ${ }^{\circledR}$ has no effect of clonogenic cell survival. The calculated DEF ranged from $0.90-1.14$ across all cell lines and all concentrations, further demonstrating the lack of dose enhancement. The predicted DEF, as described in Section 2.7, gave values of $1.00195,1.0195$ and 1.195 for concentrations of $0.2 \mathrm{mM}, 2 \mathrm{mM}$ and $20 \mathrm{mM}$ respectively. The predicted DEF suggests no observable enhancement is expected at the lower concentrations. At the highest concentrations small enhancements may be expected, but these may be mitigated by experimental uncertainties and limitations of the analytic dose enhancement approximation. 


\section{Discussion}

This study aims to quantify the potential radiosensitising effects of gadolinium-based contrast agents, to improve efficacy of treatment and to interpret how the biological effect of radiation will be affected with the use of contrast agents. The concentrations of Dotarem ${ }^{\circledR}$ chosen ranged from 0 - $20 \mathrm{mM}$, corresponding to $0-3.5 \mathrm{mgGd} \mathrm{mL}^{-1}$. The reason for this was to compare a range of values around the concentration used in the publication by Taupin et al. in which a concentration of $2.1 \mathrm{mgGd} \mathrm{mL}^{-1}$ was used (4).

We report a substantial variability in gadolinium uptake between different cell lines. This was associated with a significant increase in DNA damage 1 hour post-irradiation, although much of this damage is repaired by 24 hours. The correlation between the mass of gadolinium taken up by the cells and the levels of DNA damage for doses of 0-2 Gy indicate that Dotarem ${ }^{\circledR}$ is responsible increasing the effectiveness by which DNA lesions are formed, at $225 \mathrm{kVp}$ x-ray energy. However, despite this increased DNA damage, no change in cell survival is seen. The spectrum of energies produced may be responsible for the lack of dose enhancement, as opposed to using a monochromatic beam of one energy, as $225 \mathrm{kVp}$ is the peak energy and not the mean, with DEFs calculated to range from $0.90-1.14$ across all cell lines and concentrations of Dotarem ${ }^{\circledR}$. Only negligible enhancement is predicted the lower concentrations of Dotarem, and an enhancement similar to the greatest experimental observation (1.195) is predicted at the highest concentration. The slightly lower than expected enhancement may reflect complexities of the experimental setup, and limitations of the analytic DEF calculation.

Corresponding Author: Emily Russell. Contact Information; erussell11@qub.ac.uk, PGJCCR 97 Lisburn Road Belfast BT9 7AE. 
For clarification, the 24 hours incubation time for which the Dotarem ${ }^{\circledR}$ was treating the cells is not representative of the clinical setting, and is likely to be longer than the time between a patient being injected and receiving radiation treatment. However, there is substantial evidence in the literature of Gadolinium remaining within cells far longer than was previously thought $(11,12,46,13-19,45)$, and it is expected that the gadolinium would be removed from the cells within a similar time as would occur clinically.

The immunofluorescence DNA damage assays indicated an inherent toxicity with Dotarem $^{\circledR}$, in the absence of radiation for all cell lines. It also demonstrated a significant increase in the number of double strand breaks for all cell lines at both 1 Gy and 2 Gy dose, 1 hour post-irradiation. It has been reported in the literature that the use of glass coverslips will create a strong emission of electrons, by Kegel et al. (47). However, the values of dose enhancement from Dotarem ${ }^{\circledR}$ have been compared to the control values with no contrast, removing any potential bias. Also, the publication by Kegel et al. was irradiating cells from below the coverslip, whereas this study irradiated from above, which may have significantly reduced these effects (47). When comparing the DNA damage assay to the clonogenic assay, it must be noted that the cells in the DNA damage assay were adhered to a glass coverslip, compared to the well alone for the clonogenic assay.

In terms of radiosensitisation, it is important to outline that there are 2 contributions, the first being in terms of the cells' biological/chemical response to radiation being altered by the Dotarem ${ }^{\circledR}$. independent of dose enhancement. The second contribution is the dose enhancement caused by the increase in secondary electrons by interactions with high Z number elements. It was expected that the dose enhancement effect would be of a greater contribution, however we have demonstrated this inherent 
toxicity in the absence of radiation also, implying a significant change in the metabolic activities of the cell.

The $225 \mathrm{kVp}$ x-ray energy used here does not correspond exactly to the MV energies used for clinical radiotherapy. Firstly, the dominant photon interaction at $225 \mathrm{kVp}$ is the photoelectron effect, due to the spectrum of lower energies. Clinical MV radiation primarily deposits energy by the Compton effect. The photoelectric has an attenuation coefficient that is proportional to $Z^{3}$ compared to the Compton effect which is proportional to $Z$ (48). For this reason, tissues are more strongly absorbent of lower energy radiation, and therefore it might be expected that the dose enhancement would be seen primarily at low $\mathrm{kV}$ energies. However, this is not the only factor to consider. When comparing the absorption ratio between gadolinium and water, the larger discrepancies are predominantly in the $10-100 \mathrm{kV}$ energy range, which is cut off from the $225 \mathrm{kVp}$ spectrum (49) by the use of a $2 \mathrm{~mm}$ Cu filter. For this reason, the predicted enhancement in this study is relatively small, even at the highest concentrations, which may be more comparable to the clinical scenario.

Comparing this study to previous investigations by Taupin et al., this work is focused around 6 different human cancer cell lines, in contrast to the single rat glioma cells that were used previously (4). The study found a greater radiosensitisation at medium kV x-ray energies for gadolinium nanoparticles than with the conventional contrast agent. At 1.25 MV energy, radiosensitisation was seen with the conventional contrast agent via a clonogenic assay, for a concentration around $20 \mathrm{mM}$. This is in contrast to the work presented here, in which no sensitisation was seen with clonogenic assays at $225 \mathrm{kVp}$ compared with the $\mathrm{kV}$ energies used by Taupin et al. A major difference between the two studies is the energy spectrum of the radiation used. Whilst Taupin et al. use Corresponding Author: Emily Russell. Contact Information; erussell11@qub.ac.uk, PGJCCR 97 Lisburn Road Belfast BT9 7AE. 
monochromiatic X-rays, this study employs a polychromatic spectrum of low energy photons $<225 \mathrm{kV}$ which could average out the effects reported using synchrotron radiation considering that the reported radiation dose enhancements were highly 'energy dependent'. Another significant difference relies in the experimental technique, with Taupin et al. treating the cells whilst in suspension, compared to this study in which the cells were treated in adherence. This may impact a number of variables, including the exact dose received by cells due to the range of depths the cells would be situated, as well the nonuniform exposure to the contrast agent that may occur with cells treated in adherence.

While there is a significant increase in DNA damage using Dotarem ${ }^{\circledR} 1$ hour postirradiation, with percentage increases at $20 \mathrm{mM}$ for all cell lines ranging from $22.5-34.8 \%$, this is not detected with the clonogenic assay. This may be explained by the levels of DNA damage found 24 hours post irradiation, with the percentage of cell repair is not significantly affected by the increasing concentrations of Dotarem ${ }^{\circledR}$. It is possible that after a longer time period, perhaps 48 or 72 hours, that the percentage repair would be even higher. The inference of this result is that, whilst there is an initial increase in DNA damage, this damage is easily repairable by cells and does not inhibit the cells' ability to repair and produce colonies. Although the presence of Dotarem ${ }^{\circledR}$ increases the amount of DNA lesions, it does not appear to alter the complexity, with the additional damage repaired by either homologous recombination or non-homologous end joining (50), and not lethal to the cells.

However, it is also important to note the increase in DNA damage with Dotarem ${ }^{\circledR}$ alone without the presence of radiation. This indicates that there is an inherent DNA damage caused by the Dotarem ${ }^{\circledR}$, the extent to which is cell line specific, with MCF7 cells showing a larger amount of background DNA damage compared with the other cell lines. This suggests that the highly significant increase in DNA damage for MCF7 cells may be due Corresponding Author: Emily Russell. Contact Information; erussell11@qub.ac.uk, PGJCCR 97 Lisburn Road Belfast BT9 7AE. 
to a higher susceptibility to DNA damage. This is also evident in the correlation between the DNA damage and the gadolinium mass taken up by the cells. Another point to consider is that other cell lines, such as the HEPG2 cells, also had a considerable uptake of gadolinium, yet has less impact on any increase in DNA damage 1 hour post-irradiation.

The increase in DNA damage seen without radiation is validated by studies investigating DNA damage from patients who have received MRI contrast agents. Both Friebe et al. and Yildiz et al. that have found increased DNA damage caused by gadolinium contrast agents used in combination with MRI scanning $(8,9)$. Friebe et al demonstrated this using 5 gadolinium contrast agents (Gadovist, Dotarem ${ }^{\circledR}$, Omniscan, Magnograf and Primovist) in order to demonstrate the differences between chemical structures, whilst Yildiz et al. used Omniscan as their contrast agent. Whilst it is important to note the impact that the MRI may have, this investigation emphasises the likelihood that gadolinium contrast agents are impacting this DNA damage. The studies by Friebe et al. and Yildiz et al. measured DNA damage 15 minutes after a contrast-enhanced MRI scan that took 1 hour, and Yildiz et al. measured DNA damage immediately before, after contrast was injected, and immediately after a contrast-enhanced MRI $(8,9)$. Our study also shows this initial damage, although at 24 hours the DNA damage was mostly repaired, which is important in understanding the toxicity dynamics of gadolinium induced DNA damage. However, the increase in damage appears to be more persistent in certain cell lines, namely MCF7 and HEPG2.

The measurements taken to investigate the uptake of Dotarem ${ }^{\circledR}$ using ICP-MS goes some way to indicating whether the quantity of gadolinium taken up has an impact on the level of DNA damage caused. It seems that there is a cell line specific nature of uptake, with a range of gadolinium mass per cell for all concentrations. DU145 cells showed the highest Corresponding Author: Emily Russell. Contact Information; erussell11@qub.ac.uk, PGJCCR 97 Lisburn Road Belfast BT9 7AE. 
levels of uptake at $20 \mathrm{mM}$, but this was not the case at $0.2 \mathrm{mM}$ and $2 \mathrm{mM}$. The results indicate that certain cell lines may more actively take up the Dotarem ${ }^{\circledR}$ than others, or that they are less efficient at removing the gadolinium from the cell, dependant on the concentration. The clinical relevance of these results is that the toxicity to cells may be determined by the effectiveness by which the cells are able to remove the Dotarem ${ }^{\circledR}$.

One of the challenges with the data is that the foci numbers are small 24 hours postirradiation. The significant differences between different concentrations are still small differences, and so the levels of remaining damage may still be low enough to suggest enough DNA damage repair. The ICP-MS results are also limited by providing information only regarding the quantity of gadolinium found within each cell, without regard for the mechanisms of uptake or the subcellular location of the gadolinium. Another limitation is in the inability to distinguish the dose enhancement seen by the use of high $Z$ number elements from the biological effects of the Dotarem ${ }^{\circledR}$, in terms of the cells' response to the combination of radiation with Dotarem ${ }^{\circledR}$. Future work will aim to evaluate these effects in the presence of a magnetic field to focus on DNA damage caused by the combination of contrast agents, magnetic fields and radiation, as well as further experimentation to determine the biological impact of Dotarem ${ }^{\circledR}$ on the cells' reaction to radiation and without the presence of extra-cellular media containing Dotarem ${ }^{\circledR}$. Further work is also required to determine the effects of Dotarem ${ }^{\circledR}$ in combination with MV radiation, as an MR-Linac would conventionally use $6 \mathrm{MV} x$-rays, and so it is important to investigate whether the difference in energy would impact radiosensitising properties.

This study provides key information regarding the inherent toxicity of Dotarem ${ }^{\circledR}$. It also investigates its radiosensitising properties regarding initial levels of DNA damage.

Despite this, and in contrast to data from Taupin et al. this increased DNA damage has no Corresponding Author: Emily Russell. Contact Information; erussell11@qub.ac.uk, PGJCCR 97 Lisburn Road Belfast BT9 7AE. 
significant impact on cell survival with $225 \mathrm{kVp} x$-rays, indicating the damage is not severe across multiple cell lines. For the first time, we have correlated the mass of gadolinium uptake by human cancer cell lines with levels of DNA damage, showing a clear interrelationship.

\section{Conclusion}

This study found a significant increase in initial levels of DNA damage at 2Gy for 6 cancer cell lines following Dotarem ${ }^{\circledR}$ treatment. However, no significant impact was observed for cell survival. We conclude that, whilst initial levels of DNA damage are increased in the presence of a gadolinium contrast agent, this damage is repairable, and does not affect the cells survival.

\section{Acknowledgements}

This work is a collaboration between Queen's University Belfast, and the National Physical Laboratory, funded by the Medical Research Council (Ref: MR/P01593X/1). 
Figure 1

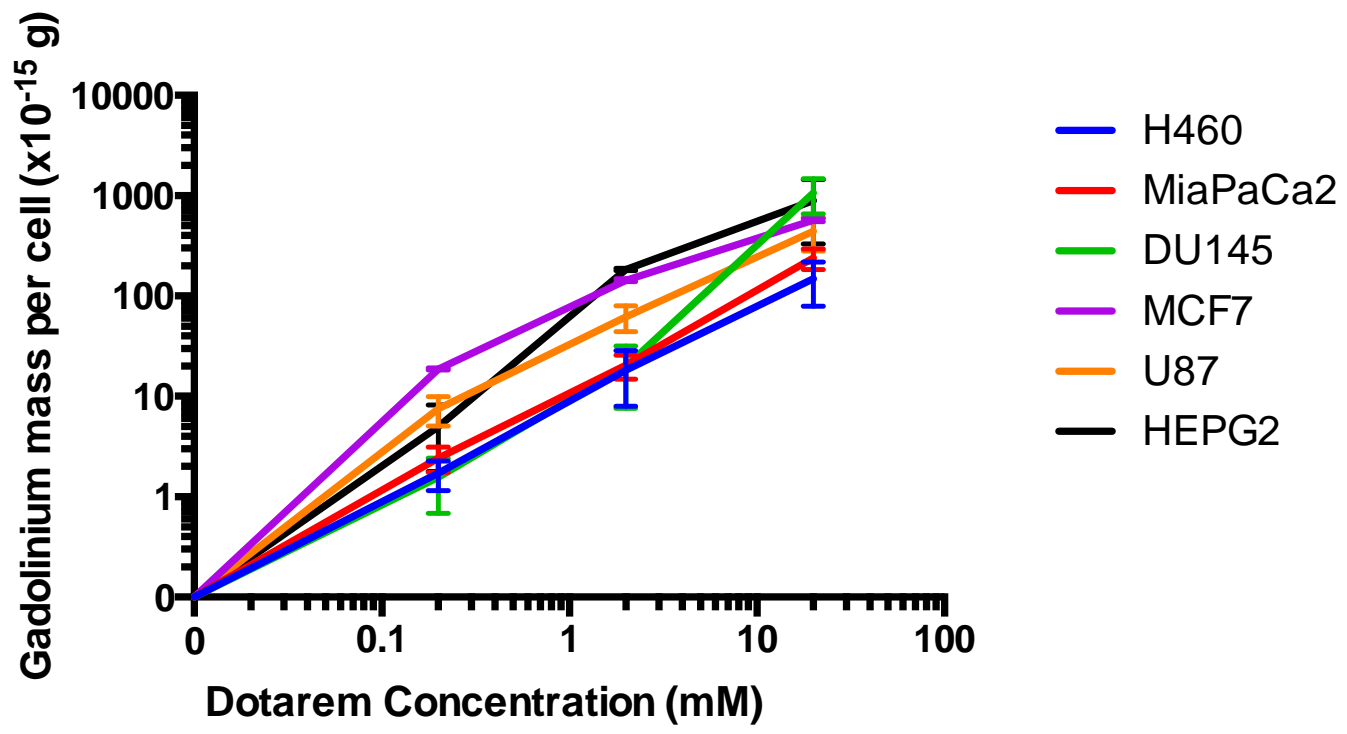




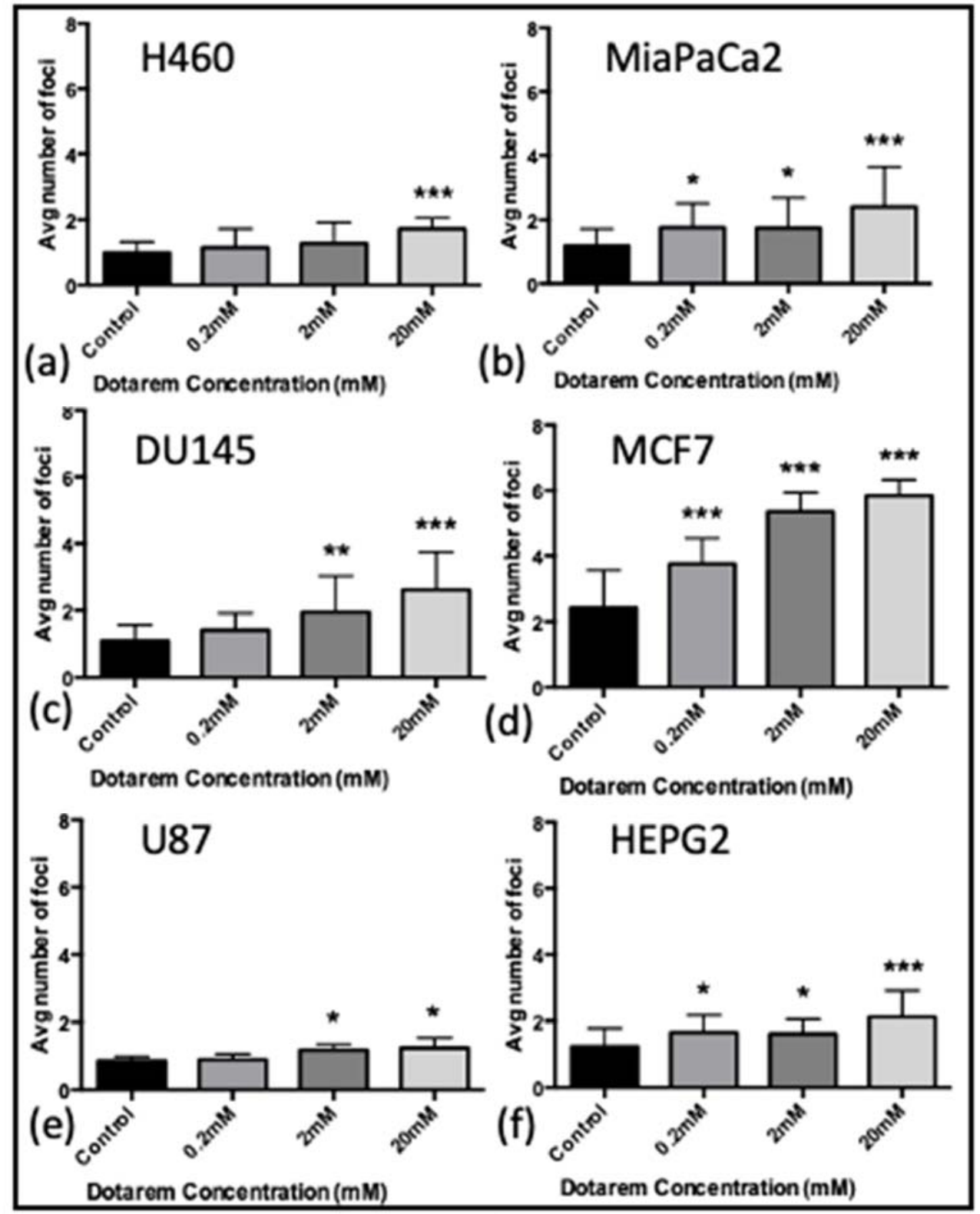

Corresponding Author: Emily Russell. Contact Information; erussell11@qub.ac.uk, PGJCCR 97 Lisburn Road Belfast BT9 7AE. 


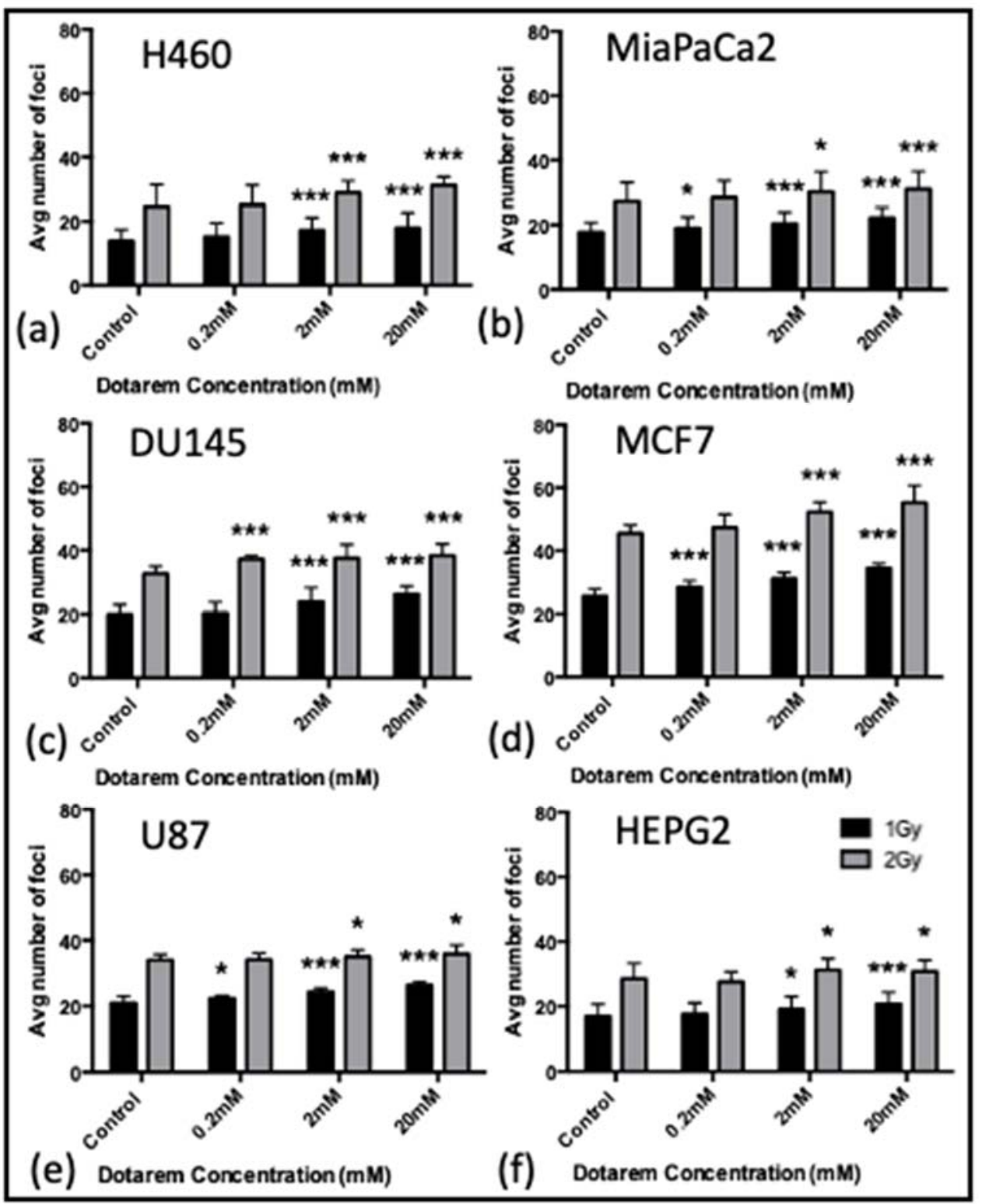

Corresponding Author: Emily Russell. Contact Information; erussell11@qub.ac.uk, PGJCCR 97 Lisburn Road Belfast BT9 7AE. 


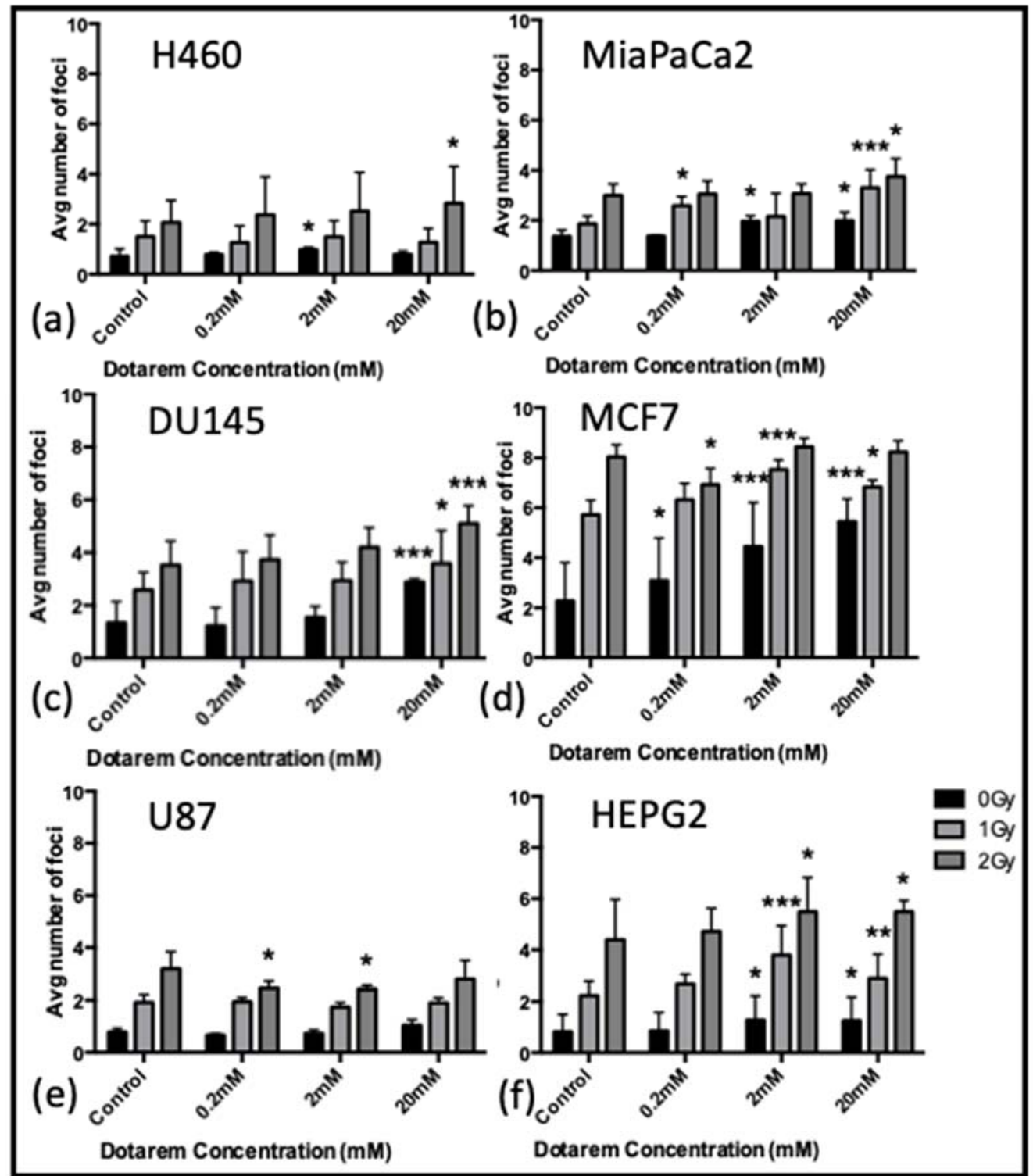

Corresponding Author: Emily Russell. Contact Information; erussell11@qub.ac.uk, PGJCCR 97 Lisburn Road Belfast BT9 7AE. 
Figure 5

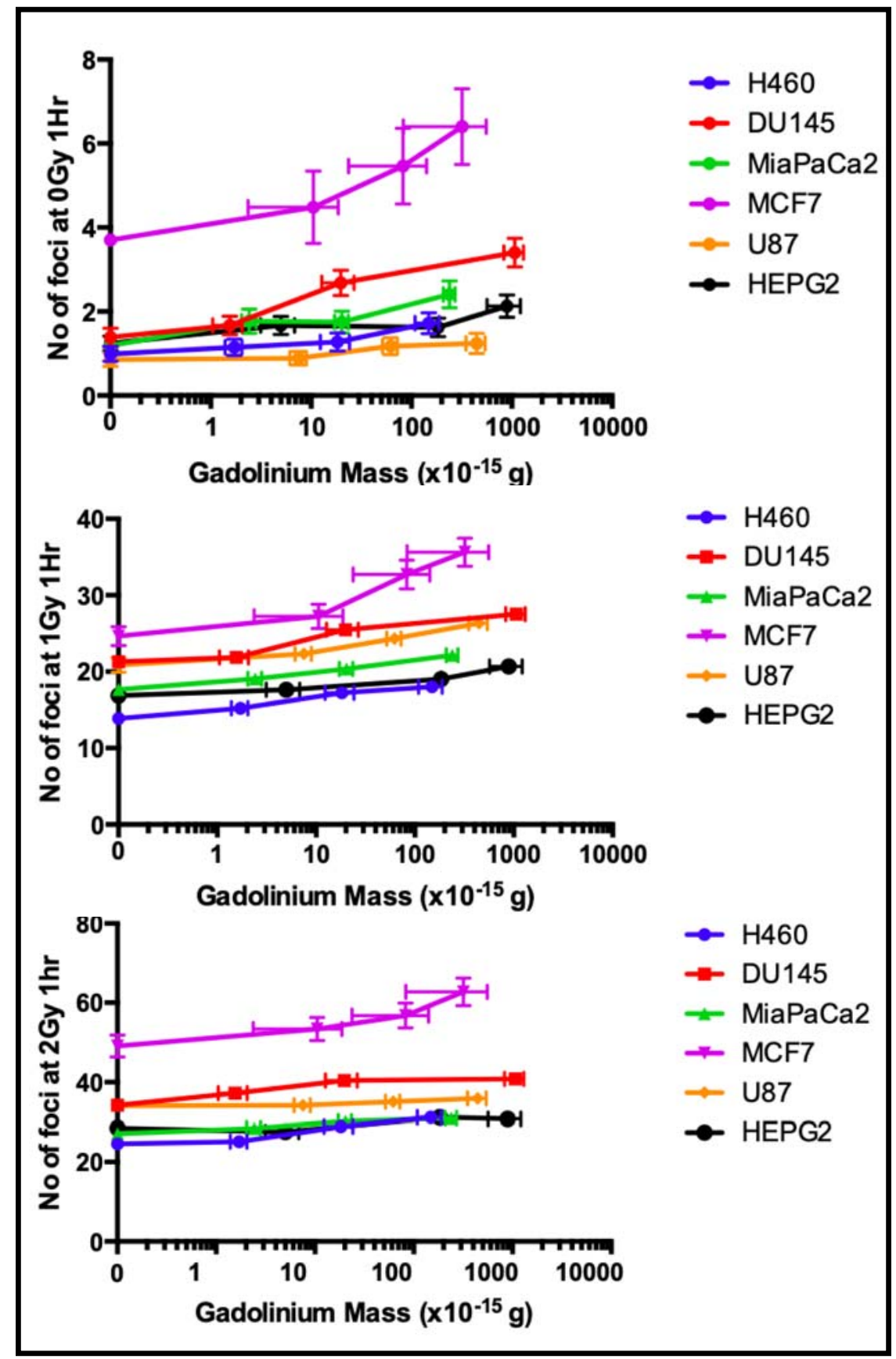

Corresponding Author: Emily Russell. Contact Information; erussell11@qub.ac.uk, PGJCCR 97 Lisburn Road Belfast BT9 7AE. 